ISEC2005-76064

\title{
FEASIBILITY STUDY OF SOLAR ADSORPTION TECHNOLOGIES FOR AUTOMOBILE AIR-CONDITIONING
}

\author{
M, O. Abdullah* and S. L. Leo \\ Mechanical \& Manufacturing System Engineering, Faculty of Engineering, \\ Universiti Malaysia Sarawak, \\ 94300 Kota Samarahan, \\ Sarawak, Malaysia.
}

\begin{abstract}
An adsorption system driven by solar heat or waste heat can help to eliminate the use of ozone depletion substances, such as chlorofluorocarbons (CFCs) and hydro-chlorofluorocarbons (HCFCs). In recent years, adsorption system has witnessed an increasing interest in many fields due to the fact that this system is quiet, long lasting, cheap to maintain and environmentally benign. Although adsorption system is not commonly used for automobile air conditioning, adsorption-cooled minirefrigerators have been marketed for recreational transports (motor homes, boats, etc). Hence, there exists a need for a creative design and innovation to allow adsorption technology to be practical for air conditioning in automobile. The objective of this paper is to present a comprehensive review on the past efforts in the field of solar adsorption refrigeration systems and also the feasibility study of this technology for automobile airconditioning purpose. It is a particularly an attractive application for solar energy because of the near coincidence of peak cooling loads with the available of solar power.
\end{abstract}

\subsection{INTRODUCTION}

Adsorption system is one of the potential solar thermal refrigeration methods [1]. This is due to the fact that solar power available is near coincident of peak cooling loads. The advantages of solar adsorption system are it is quiet, long lasting, cheap to maintain and environmental friendly [2]. In the past, adsorptive processes have been widely used for catalysis and gas separation. As adsorption technology evolved, a lot of research had been carried out (notably in China, United State of

\footnotetext{
* Corresponding author.E-mail: amomar@feng.unimas.my Tel: +6082679301 (Direct line). Fax: +6082672317
}

America, France and Japan) to study the application of this technology for heat pumps and refrigeration. However, adsorption refrigeration systems are still cannot vie with the conventional electrical-driven refrigeration systems due to their high initial capital cost. The possibility of partially solar powered the adsorption system can counterbalance its higher energy consumption. With this possibility will make them as the most environmental friendly cooling alternative from every aspect; including ozone depletion potential, global warming potential and primary energy consumption. Thus, adsorption system can be a good alternative to classical vapor-compression machines in the future.

Adsorption refrigeration cycle powered by solar energy or waste heat exhausted from engines has been successfully used for ice making and cold production. For example, solar adsorption ice maker [3], zeolite-water solar cold storage system [4], carbon-ammonia solar refrigerator for vaccine cooling [5], and a silica gel-water adsorption refrigeration cycle driven by waste heat of near-ambient temperature have been reported by Saha et al. [6]. Dieng and Wang [2] have stimulated several theoretical and experimental studies on adsorption cooling systems. They also gave useful guidelines regarding the designs parameters of adsorbent bed reactors, and the applicability of solar adsorption for both air-conditioning and refrigeration purposes. Based on the literature, extensive research has been performed on adsorption refrigeration, but research on the possibility of applying this technology for automobile air-conditioning purposes is still rare. However, with the recent advancement in the solar adsorption refrigeration technologies seems to make it possible by increasing the performance of solar adsorption unit. This paper focuses on the feasibility study of applying solar adsorption system for automobile air-conditioning purpose. 